\title{
Internet of Old Things
}

\author{
Chris Speed \\ Edinburgh College of Art \\ Lauriston Place, Edinburgh EH3 9DF \\ c.speed@eca.ac.uk \\ Angelina Karpovich \\ Brunel University \\ Kingston Lane, Uxbridge UB8 3PH \\ angelina.karpovich@brunel.ac.uk
}

\author{
Maria Burke \\ University of Salford \\ 43 The Crescent, Salford M5 4WT \\ m.e.burke@salford.ac.uk \\ Simone O'Callaghan \\ University of Dundee \\ Nethergate, Dundee DD1 4HN \\ s.p.ocallaghan@dundee.ac.uk
}

\author{
Andrew Hudson-Smith \\ University College London \\ Gower Street, London, WC1E 6BT \\ andyhudsonsmith@googlemail.com \\ Morna Simpson \\ University of Dundee \\ Nethergate, Dundee DD1 4HN \\ morna@computing.dundee.ac.uk
}

\begin{abstract}
This short paper reflects upon the temporal characteristics of the emerging phenomenon known as the Internet of Things. As objects become individually tagged with unique identities through the addition of small electronic chips or bar codes, their history is recorded and made available to others across a network. The advent of this ever-growing catalogue of histories means that every object will be 'in touch' with its current and previous owner at all times, and suggests that whilst owners might like to 'forget' about an object, we will never truly be detached from them. Such a network presents opportunities for society to reconsider how it disposes of objects and instead consider how we might pass them on to future owners. However the author suggests that current industrial interest in the potential for an Internet of Things is hindered by an adherence to a linear model of time that is more interested in the production and sale of new objects than the histories of the old.
\end{abstract}

Keywords: Internet of things, tagging, memory, time, place.

\section{CONTEXT}

The term, 'internet of things', refers to the technical and cultural shift that is anticipated as society moves to a ubiquitous form of computing in which every device is 'on', and every object is connected in some way to the internet. The specific reference to 'things' refers to the concept that every new object will also be able to part of this extended Internet, because they will have been tagged and indexed by the manufacturer during production. The technology has enabled supermarkets to track the temperature of consignments of prawns from the fishing boat that caught them, to the in-store freezers, to following the life cycle of a product from cradle to grave, shelf to landfill. Tracked and monitored as they move around the world, objects are becoming networked and 'always-on' (Greenfield, 2006), a condition that means it will become harder to disassociate an object from its memories.

\section{MODELS OF TIME}

\subsection{Staring forwards into the future}

However manufacturing isn't geared up to handling the histories of objects, it is focussed upon the production of new objects. The innovative use of linear models of time underpinned the development of manufacturing and distribution systems throughout the twentieth century. Since the industrial revolution, time and space has been treated as discrete units in order to develop more and more innovative means of accelerating production processes. From Ford's development of the production line to the Toyota Production System, time and space have been compressed to develop increasingly flexible forms of accumulation. But, in each case the model of time has travelled in a one direction: from a cradle to a grave, choosing to pay little attention to looking backwards.

Evidence of this 'forward looking production of things' are epitomised in the technologically determinist slogans from recent history: We're getting there (British Rail 1980's), Where do you want to go today? (Microsoft 1990's) or The future's bright the future's Orange (Orange phones 2000's). Symptoms of this cultural condition include a tendency toward disposal and the perception that one is able to relinquish oneself from belongings, and that memory and object can be easily separated. In the summer of 2009 the UK artist Jasper Joffe staged the sale of everything that he owned at the Idea Generation Gallery in London. Everything from his paintings, drawings, teddy bears, and rare books was grouped into 33 different lots, each on sale for $£ 3,333$. Part of the publicity for the show involved a short interview on 
BBC Radio. During this interview he described how the installation / performance offered him an opportunity to "re-think everything" and to overcome a tendency of "getting stuck with old habits".

"My emotions exist I guess in my brain, not in the stuff that I own, the things that I feel... the things I do, don't relate to the photos l've got in a box or an object that I keep at home, or you know, an antique teddy bear." Jasper Joffe, 2009

Joffe's ease in detaching himself from an object and the memories that are associated with it, are a Cartesian trait in which the breaking down of systems into discrete units, in particular the subject and object, and time and space allow for the producer to construct a position of control. The linear model of time that manufacturing models have inherited, tends toward an industrial interpretation for the Internet of Things that, like Joffe, disassociates itself with the past and is interested in only producing the new.

\subsection{Looking backwards whilst walking forward}

Whilst the consumer landscape is kept 'fresh' with information about the new, the network properties of the Internet of Things offers other opportunities that do not adhere to a forward facing model of time, and instead offer value to objects through the recovery and retention of information from the past. It has been suggested that people surround themselves with between 1,000 and 5,000 objects. Of those thousands of objects many of them are probably not truly cared for and end up in rubbish bins or in storage. But for every owner, in almost every household there are a selection of objects that hold significant resonance, and will already connect them to an 'Internet' of memory and meaning. An intrinsic human trait is the process of imbuing meaning onto objects so that they provide connections to people, events and environments. Artefacts across a mantelpiece become conduits between events that happened in the past, to people who will occupy the future. These objects become essential coordinates across families and communities to support the telling of a stories and passing-on knowledge.

Projects such as Significant Objects (http://www.significantobjects.com) attach short fictional stories to artefacts that are subsequently sold on eBay. The value added by the unique story increases the sale price of the items and changes dramatically how an object is interpreted. Similar, but a shopping 'centre' in its own right, is Pass The Baton (http://www.pass-the-baton.com/) a commercial project that allows people to attach a personal history to an object before selling it through the project website or an actual shop in
Tokyo. Both projects subvert the orthodox use of linear time by placing more emphasis upon the provenance of an object rather than projecting an aura of newness.

Operating outside of a 'sales context' but firmly within the field of The Internet of Things, the authors introduce a research project that is enabling people to tag personal objects with memories, and allow other people to review them by scanning the tag. Tales of Things (http://www.talesofthings.com) allows visitors to the website the ability to upload an image of an artefact, associate it with a story (online audio, video or text file) and generate a unique printable barcode for them. Once the barcode is attached the object, a free iPhone or Android application is able to scan the barcode and retrieve the story. The ability to add comments and further stories to artefacts as they are adopted by new owners offers a network of memory in which things are connected by subject and not time.

\subsection{MEMORY ECONOMY}

The three projects cited evoke an alternative economy, one in which the arrow of time reflects back to use memories and history as a means of adding value to artefacts as the pass through the society. And, as objects become tagged and catalogued within networks, the Tales of Things project offers a 'bottom up' approach allowing the public to tag objects and ensure that the Internet of Things isn't just focussed upon new items, but identifies the value of old things. This temporal 'turn' offers a significant shift in the linear cradle to grave production and consumption path that has underpinned the 20th century, one that in contrast offers a 'memory economy' in which value isn't predicated on the idea of the 'new', and the assumption that we can detach ourselves from things in order to move into the future without ties to the past is vanquished.

\section{ACKNOWLEDGMENTS}

The Tales of Things project is supported by a Digital Economy, Research Councils UK grant, and made 'real' by our team: Barthel, R., Blundell, B., De Jode, M., Leder, K., Manohar, M., Lee, C., Macdonald, J., Quigley, M., Rogers, J., Shingleton, D.

\section{REFERENCES}

Greenfield, A. (2006) Everyware, The Dawning Age of Ubiquitous Computing, Berkley: New Riders Castells, M. (1996) The Rise of the Network Society (Second Edition). Oxford: Blackwell. 